This is the author's final, peer-reviewed manuscript as accepted for publication. The publisher-formatted version may be available through the publisher's web site or your institution's library.

\title{
Joint logistics and financial services by a 3PL firm
}

Xiangfeng Chen, Gangshu (George) Cai

\section{How to cite this manuscript}

If you make reference to this version of the manuscript, use the following information:

Chen, X., \& Cai, G. (2011). Joint logistics and financial services by a 3PL firm.

Retrieved from http://krex.ksu.edu

\section{Published Version Information}

Citation: Chen, X., \& Cai, G. (2011). Joint logistics and financial services by a 3PL firm. European Journal of Operational Research, 214(3), 579-587.

Copyright: Copyright (C) 2011 Elsevier B.V. All rights reserved

Digital Object Identifier (DOI): doi:10.1016/j.ejor.2011.05.010

Publisher's Link: http://www.sciencedirect.com/science/article/pii/S0377221711004164

This item was retrieved from the K-State Research Exchange (K-REx), the institutional repository of Kansas State University. K-REx is available at http://krex.ksu.edu 


\title{
Joint Logistics and Financial Services by a 3PL Firm
}

\author{
Xiangfeng Chen * and Gangshu (George) Cai ${ }^{\dagger}$
}

\begin{abstract}
Integrated logistics and financial services have been practiced by third party logistics (3PL) firms for years; however, the literature has been silent on the value of 3PL firms as credit providers in budget-constrained supply chains. This paper investigates an extended supply chain model with a supplier, a budget-constrained retailer, a bank, and a 3PL firm, in which the retailer has insufficient initial budget and may borrow or obtain trade credit from either a bank (traditional role) or a 3PL firm (control role). Our analysis indicates that the control role model yields higher profits not only for the 3PL firm but also for the supplier, the retailer, and the entire supply chain. In comparison with a supplier credit model where the supplier provides the trade credit, the control role model yields a better performance for the supply chain as long as the 3PL firm's marginal profit is greater than that of the supplier. We further demonstrate that, for all players, both the control role and supplier credit models can outperform the classic newsvendor model without budget constraint.
\end{abstract}

Keywords: third party logistics (3PL); budget-constrained retailer; supply chain; financial service

${ }^{*}$ School of Management, Fudan University, Shanghai, 200433, China. Email: chenxf@fudan.edu.cn

${ }^{\dagger}$ Department of Management, Kansas State University, Manhattan, KS 66506, USA. Email: gcai@ksu.edu. Corresponding author. 


\section{Introduction}

The operations management literature used to assume "deep pockets" for firms that have unlimited budget in decision-making. However, the "deep pockets" assumption has been challenged by the reality that many retailers are budget-constrained and under increasing pressure to improve cash flow, especially during financial crises. Obviously, limited budgets would significantly hinder the development of many start-up and fast-growing companies.

Financing support from banks can help these budget-constrained retailers. For example, with the aid of a goods-ownership mortgage loan (50 million Yuan) from Shenzhen Development Bank, a professional aluminum ingots trading company grew from less than 5 million Yuan to over 600 million Yuan in one year, according to China Business News, 2002. Similar asset-based financing has played an important role for budget-constrained retailers (Barnett, 1997; Xu and Birge, 2008). However, it is challenging for banks to monitor the transactions of the products; thus, without accurate real-time information about the transactions of the products, banks might become reluctant to provide financial service, because retailers may divert the loan to other riskier projects (Burkart and Ellingsen, 2004). The above problem can be resolved by integrating logistics and financial service (ILFS), through third party logistics (3PL) firms that ally with financial institutions and provide cooperative logistics and financial solutions to budget-constrained retailers. For example, UPS owns UPS Capital; AIMS Logistics, LLC was acquired by U.S. Bank National Association in 2007; and U.S. Bank joined forces with Schneider Logistics, Inc. in 2007.

ILFS benefits the supply chain operations in two ways: (1) helping budget-constrained firms raise funds; and (2) helping firms coordinate the material flow and financial flow in the supply chain. Because of the above advantages, some major 3PL firms, such as UPS and FedEx, provide ILFS to their clients, which in turn hone their own competitive edge. For instance, UPS is selling its UPS Capital financing service along with the conventional logistics service. It provides Global Asset Based Lending (GABL) and inventory financing to its clients, which enables these clients to monetize off-shore or in-transit inventory and, hence, increases their liquidity. The practice of ILFS can also be found in developing markets. For instance, since 2006, one of China's major logistics firms, China National Foreign Trade Transportation Group Corporation (SINOTRANS) started to cooperate with the Industrial and Commercial Bank of China (ICBC) in the area of logistics 
finance. As of 2007, SINOTRANS had already allied with more than 10 banks to offer ILFS to its clients. In fact, many other successful logistics service providers, such as DHL, Exel, Kuehne and Nagel, Schenker, Panalpina, C. H. Robinson, TNT Logistics, Schneider and NYK Logistics, have also incorporated financial services into their traditional logistics services (see Lu et al., 2009).

Although recent studies (e.g., Buzacott and Zhang, 2004; Dada and Hu, 2008; Jing et al., 2010) on bank financing and trade credit are significant and promising, the extant literature has been silent on the influence of 3PL financing on a budget-constrained supply chain. A research question naturally arises: How would a 3PL firm with ILFS impact the supply chain with a budget-constrained retailer? To this end, we investigate two different roles of a 3PL firm in an extended supply chain with a supplier, a retailer, a 3PL firm, and a bank. The retailer is budget-constrained and may borrow capital from either the bank or the 3PL firm. The first role is called the traditional role, where the 3PL firm provides only the traditional logistics services in the supply chain when the retailer borrows capital from the bank. The second role is referred to as the control role, where the 3PL firm provides both logistics services and trade credit financing to the budget-constrained retailer.

Our analysis indicates that, in the traditional role model with symmetric budget information, the retailer's optimal order quantity is less than that in a classic newsvendor without budget constraint model. This is because the retailer bears additional financial burden compared with the classic newsvendor. As a result, overall supply chain efficiency is undercut because of an insufficient budget. This inefficiency can be altered in the control role model, where the 3PL firm integrates logistics and financial services and, thus, can better coordinate the supply chain by providing a lower interest rate. Moreover, the alliance of logistics and financing enables automatic monitoring of the transactions of products, thus preventing the retailer's potential concealment of budget information.

We further compare the performance of the above two roles in terms of interest-demand elasticity, which measures the responsiveness of the retailer's order quantity to the change in the interest rate. In both roles, if the order quantity is interest inelastic (i.e., interest-demand elasticity is low), the lender, either the bank or the 3PL firm, would charge the interest rate at its highest level; in doing so, the lender can maximally squeeze profit from the retailer. In the opposite extreme 
case where the order quantity is highly interest elastic (i.e., interest-demand elasticity is high), the lender would reduce the interest rate to its lowest level to encourage a bigger order. Thus, there is no difference among different models if interest-demand elasticity is too high or too low. Given that normally interest-demand elasticity is in the medium range, the lender in the control role model yields a lower interest rate than the traditional role model; thus, the retailer's order quantity is higher in the control role model. This would, in turn, benefit the supplier, the retailer, the 3PL firm, and the entire supply chain. These results provide theoretical support to current ILFS practices.

We extend our analysis to a supplier credit model where the supplier provides trade credit to the budget-constrained retailer. We find the control role model outperforms the supplier credit model for the players in terms of their profits, if the 3PL firm's marginal profit in the control role model is higher than the supplier's marginal profit in the supplier credit model, or vice versa. This is because a higher marginal profit renders a cushion for the lender to charge a lower interest rate, which, in turn, results in a bigger order from the retailer and then boosts overall supply chain efficiency. This result demonstrates that the control role can be quite attractive if the supply market is very competitive, such that the supplier's marginal profit is relatively lower. In both the control role and supplier credit models, the retailer with budget constraint could, though not always, order more than the classic newsvendor model without budget constraint, because either the 3PL firm or the supplier will share a higher risk of demand uncertainty by offering trade credit financing to the budget-constrained retailer. The numerical analysis further indicates that, for the players, the control role and supplier credit models can conditionally outperform the classic newsvendor model without budget constraint, especially when the initial budget is low, or high but constrained. This outcome occurs because when the initial budget is low, the retailer orders a relatively large quantity due to limited liability; and when the initial budget is sufficiently high but still constrained, the benefit of financial gain from ordering a larger quantity surpasses the potential risk of demand uncertainty.

Our paper contributes to the literature in three main ways. First, it bridges the literature gap on the 3PL trade credit/financing and provides theoretical support to current practices by the 3PL industry. Second, we also extend our analysis to compare the 3PL control role model with the supplier credit model in terms of players' profits. Third, we perform an analysis from the 
perspective of interest-demand elasticity and highlight the value of finance service by a 3PL firm with respect to the retailer's initial budget.

The remainder of the paper is organized as follows. We review the literature in Section 2. We describe the model and analyze the traditional role in Section 3. We then explore the control role of the 3PL firm in Section 4, where the comparison of two different roles is made as well. We extend our discussion to the supplier trade credit model in Section 5 and conclude in Section 6. All proofs are given in the Appendix (see online supplemental).

\section{$2 \quad$ Literature Review}

Since our paper is focused on the budget-constrained retailer in a newsvendor model, there are several threads of related literature. In the economics literature, researchers show that the buyer's budget constraints may influence the optimal mechanism of supply/procurement contracts. For instance, Levaggi (1999) develops a principal-agent model in which the principal (buyer) faces a binding budget constraint, and argues that the budget constraint does not ensure the principal is always better off by using an incentive compatible contract. Hence, the likely outcome is either a pooling or bargaining solution. Che and Gale (2000) argue that a buyer's budget constraint may make it optimal for the seller to use nonlinear pricing, commit to a declining price sequence, require that the buyer disclose its budget, or offer financing. Thomas (2002) studies the non-linear pricing problem when a budget constraint limits the magnitude of monetary transfer.

The finance literature has mostly studied a firm's integrated investment decisions which influences its capacity size and debt decisions, and, thus, has implicitly studied a firm's integrated operational and financial decisions from a perspective different from ours. For example, Dotan and Ravid (1985) show that investment and financial decisions must be made simultaneously and that a negative relationship exists between capacity expansion and financial leverage. Dammon and Senbet (1988) analyze how corporate and personal taxes influence a firm's optimal investment and financial decisions under uncertainty. They show that, when equity investment is allowed to adjust optimally, the existing prediction about the relationship between investment-related and debt-related tax shields must be modified. Mello and Parsons (1992) examine the operational decisions of a mine under all-equity financing policy, in which the mine is partially financed to maximize 
leveraged equity value. Finally, Mauer and Triantis (1994) analyze the case where a firm has the flexibility to shut down and reopen its production facility in response to price fluctuations.

The operations management literature has been prolific on newsvendor models (see Chen and Bell (2009); Chung et al. (2009); Hu et al. (2010); Lau and Lau (1999); Parlar and Weng (2003); Zhou and Wang (2009)) on which our model is based; however, most studies on the interface between operations and financial management have been recent (Caldentey and Haugh, 2009). The existing literature has focused on the budget-constrained firm's production, inventory, capacity, and debt decisions, and seeks to demonstrate that it is important to incorporate financial decisions into operational decisions. For example, Buzacott and Zhang (2004) consider a production/inventory control model and investigate the interplay between inventory decisions and asset-based financing. In their model, a retailer finances its operations by borrowing from a commercial bank. The terms of the loans are structured contingent upon the retailer's balance sheets and income statements (in particular, inventories and receivables). The authors conclude that asset-based financing allows retailers to enhance their cash return over what it would be if they were only able to use their own capital and show the importance of joint production and financial decisions in a model with a start-up company, where the ability to grow the firm is mainly constrained by its limited capital and depends on bank loans. They also explain the motivation for asset-based financing by analyzing the decision making of a bank and a set of retailers with different budgets. Hu and Sobel (2005) use a dynamic newsvendor model with the aim of maximizing the expected present value of dividends by analyzing the interdependence of a firm's capital structure and its short-term operational decisions involving inventory, dividends, and liquidity. Chao et al. (2008) use a multi-period inventory model to study the interaction between financial and operational decisions, and show that it is essential for the retailers to incorporate financial considerations into their operational decisions, especially for retailers who are short of capital. Boyabatli and Toktay (2006) analyze the impact of capital market imperfection on a firm's operational and financial decisions in a capacity investment setting, where the firm's limited budget, depending partly on tradable assets, can be increased by borrowing from the external market (commercial loan collateralized by physical assets), and its distribution can be altered with financial risk management (using forward contract to reduce the financial risk of tradable asset). In Kouvelis and Zhao (2008), the supplier takes a proactive role in offering different types of contracts designed to provide financial services to the budget-constrained retailer. 
Probably the most closely related article is by Dada and $\mathrm{Hu}$ (2008), who seminally consider a similar model to our traditional role model where a bank provides a loan to the retailer, and characterize the Stackelberg equilibrium. They further suggest a mechanism to partially coordinate the supply chain. Note that the first part of our analysis in bank financing (traditional role) is similar to theirs. Nevertheless, different from their model, we transferred a bi-level optimal problem into a one-level optimal problem that is unimodal or monotonic and can be inferred analytically, as shown in Proposition 1. It is worth noting that the biggest difference between our model and theirs is that our model allows financing from the 3PL firm and the supplier. Moreover, none of the above work has explicitly discussed the impact of different roles of a 3PL firm in a supply chain.

\section{The Model and Traditional Role}

We study an extended supply chain with a supplier, a retailer, a bank, and a 3PL firm. The retailer orders a product from the supplier and faces a random demand $D$, which follows a cumulative distribution function $F$ with density $f$. Different from the classic newsvendor problem, the transportation of the product is explicitly considered, where the retailer hires a 3PL firm to complete the transportation. Moreover, as the focus of our model, the retailer is budget-constrained and would borrow capital, either a cash loan or trade credit, from the bank, the 3PL firm, or the supplier. To be in line with Buzacott and Zhang (2004) and Dada and Hu (2008), we assume the retailer has limited liability. We use superscripts $S, R, B K$, and $3 P L$ to denote the supplier, the retailer, the bank, and the 3PL firm, respectively.

We define the hazard function $h(D)=f(D) / \bar{F}(D)$ and the Generalized Failure Rate (GFR) $H(D)=D h(D)$ in terms of the uncertain demand (see Lariviere and Porteus, 2001), where the term $\bar{F}(D)$ is defined as the tail distribution $\bar{F}(D)=1-F(D)$. We also impose the following assumption to establish the existence and uniqueness of the equilibrium of the problem, which is satisfied by most popular distributions such as the log-Normal, Exponential, Normal, Uniform, Weibull and Gamma distributions (Lariviere and Porteus, 2001).

Assumption A1. The demand distribution function $F(D)$ satisfies the following properties:

$i$ It is absolutely continuous with density $f(D)>0$ in $(a, b)$, for $0 \leq a \leq b \leq \infty$. 


\section{ii It has a finite mean $\bar{D}$.}

iii The hazard function $h(D)$ is increasing in $D \geq 0$ (IGFR).

The order quantity of the retailer to the supplier is $Q(B)$, where $B$ denotes the initial budget/capital of the retailer. The unit price of the product is denoted by $p$, which is normalized to 1 for brevity (see, e.g., Gerchak and Wang, 2004). ${ }^{1}$ The wholesale price of the product is denoted by $w_{p}$ and the unit logistic price/rate is $w_{l}$. Hence, the unit wholesale and transportation cost to the retailer is given by $w=w_{p}+w_{l}$. Let $c_{p}$ represent the unit production cost and $c_{l}$ the unit logistic operational cost. We also denote $C_{c l}=w_{p}+c_{l}$ as the total cost incurred to the retailer and the $3 \mathrm{PL}$ firm in the $3 \mathrm{PL}$ trade credit case. Similarly, $C_{s c}=w_{l}+c_{p}$ denotes the total cost incurred by the supplier and the retailer in the supplier trade credit case. Without loss of generality, we assume $c_{l}<w_{l}, c_{p}<w_{p}$, and $(1+r) w<1$, where $r$ is the interest rate in its general form and its variants will be defined as the need arises. Thus, we have $C_{c l}, C_{s c}<w$. The amount of capital that the retailer borrows is $(w Q(B)-B)^{+}$with an interest rate of $r(B)$, where $x^{+}=\max \{x, 0\}$. After demand is realized, the retailer needs to pay back $(w Q(B)-B)^{+}(1+r(B))$ to the lender; however, if the retailer's total revenue is not sufficient such that $\min \{D ; Q(B)\}<(w Q(B)-B)^{+}(1+r(B))$, the retailer declares bankruptcy and the lender collects $\min \{D ; Q(B)\}$ instead of $(w Q(B)-B)^{+}(1+r(B))$, since the retailer has limited liability. Provided that the retailer would raise funds from the bank if $B \leq w \bar{F}^{-1}(w(1+\tilde{r}(B)))$, the interest rate feasible region is given by $[0, \tilde{r}(B)]$, where $\tilde{r}(B)=\frac{\bar{F}(B / w)-w}{w}$.

To explore the influence of 3PL on the budget-constrained retailer and the supply chain, we study two scenarios: traditional and control roles of the 3PL firm. In the traditional role, the 3PL firm provides only transportation service for the retailer while the retailer borrows from the bank. In the control role, the 3PL firm provides both transportation and trade credit to the retailer. We will also compare these two roles with an extended model where the supplier provides trade credit, which is referred to as supplier credit, to the budget-constrained retailer. The classic newsvendor without budget constraint is a benchmark model, which is referred to as classic newsvendor throughout

\footnotetext{
${ }^{1}$ At the end of the Appendix, we perform an additional analysis on the case where $p$ is not normalized to demonstrate that our qualitative results sustain regardless of this normalization. We also refer readers to Dada and Hu (2008) for some useful discussion of the impact of $p$ on the optimal solution in the traditional role model.
} 
this paper. Recall that, in the classic newsvendor model with no budget constraint, the retailer's optimal solution $Q_{N}$ solves the optimal problem: $\max _{Q} E \min [D, Q]-\left(w_{p}+w_{l}\right) Q$, which can be rewritten as

$$
\max _{Q} \mathbb{E} \min [D, Q]-w Q
$$

Based on Hadley and Whitin (1963), the retailer's optimal solution $Q_{N}$ solves the equation $\bar{F}\left(Q_{N}\right)=$ $w$.

We use subscripts $t, c l, s c$, and $N$ to denote the traditional role, control role, supplier credit, and classic newsvendor models. In line with the existing literature (see Dada and $\mathrm{Hu}, 2008$; Kouvelis and Zhao, 2008), and references therein), we adopt a two-stage Stackelberg game where the lender, either the bank, the 3PL, or the supplier, determines the interest rate in the first stage, and then the retailer, as the follower, determines the optimal order quantity. In our analysis, we solve the game backwards. In the following, we first perform analysis for the case of traditional role.

\subsection{The Traditional Role}

In the case of traditional role, we will investigate two subcases: symmetric and asymmetric budget information, in terms of whether the bank will have full information of the retailer's initial budget.

\section{Symmetric Budget Information}

In the traditional role, the budged-constrained retailer would borrow $\left(w Q_{t}(B)-B\right)^{+}$from the bank. The 3PL firm provides transportation service to the retailer. Under symmetric budget information, the initial budget, $B$, of the retailer is common knowledge. Given an interest rate $r_{t}(B)$, the retailer's profit can be written as follows.

$$
\begin{aligned}
\Pi_{t}^{R}(B) & =\max _{Q_{t}(B) \geq 0} \mathbb{E}\left\{\left[\min \left[D, Q_{t}(B)\right]-\left(w Q_{t}(B)-B\right)\left(1+r_{t}(B)\right)\right]^{+}-B\right\} \\
& =\max _{Q_{t}(B) \geq 0}\left\{\int_{\left(w Q_{t}(B)-B\right)\left(1+r_{t}(B)\right)}^{Q_{t}(B)} \bar{F}(D) d D-B\right\} .
\end{aligned}
$$

If $\min \left[D, Q_{t}(B)\right]>\left(w Q_{t}(B)-B\right)\left(1+r_{t}(B)\right)$, the retailer pays back the loan plus interest to the bank; otherwise, the retailer could only pay back $\min \left[D, Q_{t}(B)\right]$. Solving the optimal order quantity yields the following proposition. 
Lemma 1 1. For the budget-constrained retailer and a given interest rate $r_{t}(B)$, the optimal order quantity $Q_{t}^{*}(B)$ is given by

$$
Q_{t}^{*}(B)= \begin{cases}\bar{F}^{-1}(w) & \text { if } \quad B \geq w \bar{F}^{-1}(w) \\ \frac{B}{w} & \text { if } \quad w \bar{F}^{-1}(w(1+\tilde{r}(B)))<B<w \bar{F}^{-1}(w), \\ \hat{Q}_{t}(B) & \text { if } \quad B \leq w \bar{F}^{-1}(w(1+\tilde{r}(B)))\end{cases}
$$

where $\hat{Q}_{t}(B)$ is implied by $\bar{F}\left(Q_{t}(B)\right)=w\left(1+r_{t}(B)\right) \bar{F}\left[\left(w Q_{t}(B)-B\right)\left(1+r_{t}(B)\right)\right]$.

2. $\hat{Q}_{t}(B)$ is unique and decreases in $r_{t}(B) \in[0, \tilde{r}(B)]$.

We attribute the first part of Lemma 1 to Dada and $\mathrm{Hu}$ (2008). Based upon the limited budget, the retailer's optimal order quantity is affected by the initial budget and interest rate. As a special case, if the initial budget is sufficient $\left(B \geq w \bar{F}^{-1}(w)\right)$, the retailer would not borrow from the bank, which is equivalent to the classic newsvendor problem without budget constraint. In the second case of Equation (2), the retailer's initial budget is not sufficient to place an ideal order; however, the interest rate is too high such that it is not profitable for the retailer to borrow from the bank. In the third case where the initial budget is significantly low, the retailer will borrow $\left(w \hat{Q}_{t}(B)-B\right)^{+}$from the bank. It is intuitive that the order quantity decreases as the interest rate increases. To make our discussion interesting, we will focus on the third case in the sequel.

Given the retailer's optimal order quantity and a loan value of $B$, the bank's profit can be written as follows.

$$
\begin{aligned}
\Pi_{t}^{B K}(B) & =\max _{0 \leq r_{t}(B) \leq \tilde{r}(B)} \mathbb{E}\left\{\min \left[\min \left[D, \hat{Q}_{t}(B)\right],\left(w \hat{Q}_{t}(B)-B\right)\left(1+r_{t}(B)\right)\right]-\left(w \hat{Q}_{t}(B)-B\right)\right\} \\
& =\max _{0 \leq r_{t}(B) \leq \tilde{r}(B)}\left\{\int_{0}^{\left(w \hat{Q}_{t}(B)-B\right)\left(1+r_{t}(B)\right)} \bar{F}(D) d D-\left(w \hat{Q}_{t}(B)-B\right)\right\} .
\end{aligned}
$$

If $\min \left[D, \hat{Q}_{t}(B)\right] \geq\left(w \hat{Q}_{t}(B)-B\right)\left(1+r_{t}(B)\right)$, the bank earns a profit of $\left(w \hat{Q}_{t}(B)-B\right) r_{t}(B)$; otherwise, the bank liquidates the retailer and yields $\min \left[D, \hat{Q}_{t}(B)\right]-\left(w \hat{Q}_{t}(B)-B\right)$. The optimal interest rate is suggested in the following proposition.

Proposition 1 In a traditional role model with symmetric budget information, the optimal interest 
rate $r_{t}^{*}(B)$ for the bank is

$$
r_{t}^{*}(B)= \begin{cases}\tilde{r}(B) \quad \text { if } \epsilon_{t}(\tilde{r}(B)) \leq 1, \\ 0 & \text { if } \epsilon_{t}(0) \geq 1, \\ \hat{r}_{t}(B) \quad \text { if } \quad \epsilon_{t}(0)<1 \quad \text { and } \epsilon_{t}(\tilde{r}(B))>1 .\end{cases}
$$

The unique $\hat{r}_{t}(B)$ is implied by $\epsilon_{t}\left(r_{t}(B)\right)=1$, where $\epsilon_{t}\left(r_{t}(B)\right)=\frac{\bar{F}\left(\hat{Q}_{t}(B)\right)\left[1-\frac{w \hat{Q}_{t}(B)-B}{w} h\left(\hat{Q}_{t}(B)\right)\right]}{w\left[1-H\left[\left(w \hat{Q}_{t}(B)-B\right)\left(1+r_{t}(B)\right)\right]\right]}$ and $\epsilon_{t}\left(r_{t}(B)\right)$ increases in $r_{t}(B) \in[0, \tilde{r}(B)]$.

We define $\epsilon_{t}\left(r_{t}(B)\right)$ as interest-demand elasticity, which measures the responsiveness of order quantity to changes in the interest rate. If $\epsilon_{t}(\tilde{r}(B)) \leq 1$, the order quantity is considered inelastic to the interest rate change. In this case, $\frac{d \prod_{t}^{B K}(B)}{d r_{t}(B)} \geq 0$, and hence the bank's financial benefit by charging a higher interest rate outweighs the gain from a bigger loan resulting from a larger order quantity. Thus, the bank will charge the interest rate at its highest level, $\tilde{r}(B)$. On the other hand, if $\epsilon_{t}(0) \geq 1$, where interest-demand is very elastic, the bank's gain from a larger order quantity outweighs the benefit of a higher interest rate, such that $\frac{d \prod_{t}^{B K}(B)}{d r_{t}(B)} \leq 0$. Thus, the bank will set the interest rate to its lowest level, zero. Between the above two extreme cases, in the middle case where $\epsilon_{t}(0)<1$ and $\epsilon_{t}(\tilde{r}(B))>1$, a unique interest rate, $\hat{r}_{t}(B)$, as defined in Proposition 1, will balance the tradeoff between the financial and operational gains. We further illustrate the above finding in Figure 1 of Section 5.2.

\section{Asymmetric Budget Information}

The above analysis is based on a symmetric information assumption in which the budget information is common knowledge to both the retailer and bank. However, in practice, the bank might have incomplete information about the retailer's initial budget. As a result, the retailer may conceal true budget information, as demonstrated by the following observation.

Lemma 2 Under asymmetric information, the budget-constrained retailer has an incentive to overstate its initial budget to the bank.

The above result occurs because the bank would charge a lower interest rate on the loan if the retailer has a higher initial budget that imposes a lower risk on the bank. However under 
asymmetric information, the retailer may take advantage of this characteristic and deliberately report a false but higher initial budget. Consequently, the bank's risk becomes higher and the expected profit goes down. If the bank suspects the retailer might have exaggerated the initial budget but cannot effectively obtain true budget information, the bank could refuse to provide loans to the budget-constrained retailer. Lemma 2 is consistent with the principal-agent theory in that, under asymmetric information, a lower quality agent/retailer has an incentive to behave like a higher quality agent/retailer. The design of adverse selection is to provide a screening instrument, such as collateral, to properly categorize the retailers by type. In a developed market, a security guarantee based on the retailer's assets could be available; however, in developing markets, many budget-constrained retailers are fast-growing or start-up companies that cannot afford to offer enough securities as the collateral for commercial loans.

In the traditional role model, the 3PL firm provides the transportation service only and does not provide any screening effect as suggested in adverse selection. However, if the 3PL firm forms an alliance with the bank, then the 3PL firm could monitor the transaction of products from the supplier to the retailer for the bank. Consequently, the retailer's false revelation of the initial budget would be discovered and prohibited. A similar process can be seen in the aforementioned cooperation between SINOTRANS and ICBC. In the following section, we will present the case where the retailer would borrow directly from the 3PL firm who provides the logistics and trade credit simultaneously, which can be seen in the practices of UPS, a 3PL firm providing financial service through its finance subsidiary UPS capital.

\section{The Value of 3PL Financing}

In this section, we first discuss the control role case where the 3PL firm provides financial services and then demonstrate the value of the 3PL firm in the financing of the budget-constrained retailer.

\subsection{The Control Role}

In the control role model, the 3PL firm provides not only logistics services but also trade credit to the retailer. While the retailer has insufficient capital to order directly from the supplier, the 3PL 
firm procures the products from the supplier for the retailer through trade credit financing and then transports them to the retailer. In addition, the 3PL firm can effectively track and monitor the transaction of products in addition to providing trade credit to the budget-constrained retailer.

In the first stage of the Stackelberg game, the 3PL firm offers a trade credit contract $\left(w, r_{c l}(B)\right)$, and in the second stage, the retailer orders $Q_{c l}^{*}(B)$ from the supplier through the 3PL firm. The retailer's decision process is the same as in the traditional role model. The 3PL firm's profit is given as follows.

$$
\begin{aligned}
\prod_{c l}^{3 P L}(B)= & \left.\max _{0 \leq r_{c l}(B) \leq \tilde{r}(B)} \mathbb{E} \min \left[\min \left[D, Q_{c l}^{*}(B)\right] ;\left(w Q_{c l}^{*}(B)-B\right)\left(1+r_{c l}(B)\right)\right\}+B-C_{c l} Q_{c l}^{*}(B)\right] \\
= & \max _{0 \leq r_{c l}(B) \leq \tilde{r}(B)} \mathbb{E}\left\{\left(w-C_{c l}\right) Q_{c l}^{*}(B)+\left(w Q_{c l}^{*}(B)-B\right)^{+} r_{c l}(B)\right. \\
& \left.-\left(\min \left[D, Q_{c l}^{*}(B)\right]-\left(w Q_{c l}^{*}(B)-B\right)\left(1+r_{c l}(B)\right)\right)^{-}\right\}
\end{aligned}
$$

where $C_{c l}=w_{p}+c_{l}$ represents procurement and logistics operational costs incurred to the 3PL firm and $x^{-}=\min \{x, 0\}$. The above payoff consists of two components: the operational revenue $\left(w-C_{c l}\right) Q_{c l}^{*}(B)$ and the financial revenue $\left(w Q_{c l}^{*}(B)-B\right) r-\left(\min \left[D, Q_{c l}^{*}(B)\right]-\left(w Q_{c l}^{*}(B)-B\right)(1+\right.$ $\left.\left.r_{c l}(B)\right)\right)^{-}$. It is straightforward that the operational profit is positive as long as $w>C_{c l}$; however, the financial profit could end up with a negative value if demand uncertainty is too high; as a result the retailer could not repay the trade credit plus interest. Thus, a tradeoff occurs: on the one hand, the $3 \mathrm{PL}$ would like to choose a small $r_{c l}(B)$ to improve operational performance; on the other hand, the 3PL would like to choose a large $r_{c l}(B)$ to satisfy his financial motive. The 3PL firm optimizes its trade credit contract while taking both motives into consideration. We characterize the optimal interest rate in the following proposition.

Proposition 2 In the control role model, the optimal interest rate $r_{c l}^{*}(B)$ for the $3 P L$ firm financing is

$$
r_{c l}^{*}(B)= \begin{cases}\tilde{r}(B) \quad \text { if } \quad \epsilon_{c l}(\tilde{r}(B)) \leq 1, \\ 0 & \text { if } \epsilon_{c l}(0) \geq 1, \\ \hat{r}_{c l}(B) \quad \text { if } \quad \epsilon_{c l}(0)<1 \quad \text { and } \quad \epsilon_{c l}(\tilde{r}(B))>1 .\end{cases}
$$

The unique $\hat{r}_{c l}(B)$ satisfies $\epsilon_{c l}\left(r_{c l}(B)\right)=1$, where $\epsilon_{c l}\left(r_{c l}(B)\right)=\frac{\bar{F}\left(Q_{c l}^{*}(B)\right)\left[1-H\left(Q_{c l}^{*}(B)\right)+\frac{B}{w} h\left(Q_{c l}^{*}(B)\right)\right]}{C_{c l}\left[1-H\left[\left(w Q_{c l}^{*}(B)-B\right)\left(1+r_{c l}(B)\right)\right]\right]}$ and $\epsilon_{c l}\left(r_{c l}(B)\right)$ increases in $r_{c l}(B) \in[0, \tilde{r}(B)]$. 
In Proposition 2, if the order quantity is inelastic to the interest rate change, where $\epsilon_{c l}\left(r_{c l}(B)\right) \leq$ $\epsilon_{c l}(\tilde{r}(B)) \leq 1$ and hence $\frac{d \prod_{c l}^{3 P L}(B)}{d r_{c l}(B)} \geq 0$, the 3PL firm charges the interest rate at the highest level, $\tilde{r}(B)$, to optimize his profit. If the order quantity is very elastic to the interest rate, where $\epsilon_{c l}\left(r_{c l}(B)\right) \geq \epsilon_{c l}(0) \geq 1$ and hence $\frac{d \prod_{c l}^{3 P L}(B)}{d r_{c l}(B)} \leq 0$, the 3PL firm achieves its optimum by completely waiving the interest for the retailer. When interest-demand elasticity is in the medium range, the 3PL firm can find a unique optimal interest rate that balances the tradeoff between the financial and operational benefits. In reality, the benefit of a control role model can be even more significant because the 3PL firm can reduce logistics costs $\left(c_{l}\right)$ by taking advantage of the economy of scale by grouping many retailers together.

\subsection{Comparison of the 3PL's Roles}

We are now in a position to compare the values of 3PL in the traditional and control roles. For brevity, we assume that the traditional role has symmetric budget information in the sequel unless mentioned otherwise.

Lemma 3 The optimal order quantity in the control role model is no less than that in the traditional role model; while the interest rate in the control role model is no more than that in the traditional role model.

Lemma 3 suggests that the optimal interest rate in the control role is no higher than that in the traditional role. The optimal order quantity in the control role is no less than that in the traditional role. The inequality holds when interest-demand elasticity is in the medium range. This result occurs because the 3PL firm shares a higher risk of demand uncertainty through the financial service and would like to reduce the interest rate to stimulate a higher order from the retailer. If interest-demand elasticity $(\epsilon)$ is either too large or too small for both traditional and control roles, the optimal interest rates are reached at the boundary; thus, the optimal interest rates and order quantities are the same in both cases.

From the proof of Lemma 3, we can obtain additional technical details, as illustrated in Table 1. The itemized results in Table 1 are determined by the interplay of interest-demand elasticity rates in both the control and traditional roles. From the proof of Lemma 3, we know that, for any given 
Table 1: Optimal interest rates and ordering quantities in traditional and control roles

\begin{tabular}{|c|c|c|c|c|c|}
\hline$\epsilon_{c l}\left(r_{c l}(B)\right)$ & $\epsilon_{t}\left(r_{t}(B)\right)$ & Elasticity $(\epsilon)$ & $r_{c l}^{*}(B)$ & $r_{t}^{*}(B)$ & $Q_{c l}^{*}\left(r_{c l}(B)\right) \& Q_{t}^{*}\left(r_{t}(B)\right)$ \\
\hline$\epsilon_{c l}(\tilde{r}) \leq 1$ & $\epsilon_{t}(\tilde{r}) \leq \epsilon_{c l}(\tilde{r}) \leq 1$ & Low & $\tilde{r}$ & $\tilde{r}$ & \multirow{2}{*}{ Indifference } \\
\hline$\epsilon_{c l}(0) \geq 1$ & $\epsilon_{c l}(0) \geq \epsilon_{t}(0) \geq 1$ & High & 0 & 0 & \\
\hline \multirow[b]{2}{*}{$\epsilon_{c l}(0) \geq 1$} & $\epsilon_{t}(\tilde{r}) \leq 1$ & \multirow{4}{*}{ Medium } & 0 & $\tilde{r}$ & $Q_{c l}^{*}(0)>Q_{t}^{*}(\tilde{r})$ \\
\hline & $\epsilon_{t}(0)<1, \epsilon_{t}(\tilde{r})>1$ & & 0 & $\hat{r}_{t}$ & $Q_{c l}^{*}(0)>Q_{t}^{*}\left(\hat{r}_{t}\right)$ \\
\hline \multirow{2}{*}{$\epsilon_{c l}(0)<1, \epsilon_{c l}(\tilde{r})>1$} & $\epsilon_{t}(\tilde{r}) \leq 1$ & & $\hat{r}_{c l}$ & $\tilde{r}$ & $Q_{c l}^{*}\left(\hat{r}_{c l}\right)>Q_{t}^{*}(\tilde{r})$ \\
\hline & $\epsilon_{t}(0)<1, \epsilon_{t}(\tilde{r})>1$ & & $\hat{r}_{c l}$ & $\hat{r}_{t}$ & $Q_{c l}^{*}\left(\hat{r}_{c l}\right) \geq Q_{t}^{*}\left(\hat{r}_{t}\right)$ \\
\hline
\end{tabular}

interest rate, interest-demand elasticity in the control role is no less than that in the traditional role. If both interest-demand elasticity rates are low, a low interest rate does not stimulate much demand; thus, the 3PL/bank will charge the interest rate at its highest level in both the control and traditional models. In contrast, if both interest-demand elasticity rates are high, the benefit from a higher demand will overweigh the benefit of a higher interest rate; in this case, the 3PL/bank will charge a zero interest rate in both the control and traditional role models. If interest-demand elasticity is in the medium range, the interest rates in both models will differ in the four subcases, as shown in Table 1. Nevertheless, the optimal interest rate in the control role is no more than that in the traditional role; while the optimal order quantity in the control role weakly dominates that in the traditional role.

Owing to a higher order quantity in the control role, we may expect that the entire supply chain will be more efficient in the control role, which is confirmed by the following proposition.

Proposition 3 For the 3PL firm, retailer, and supplier, the control role model outperforms the traditional role model.

Proposition 3 is a natural result from Lemma 3, because in the control role model, compared with the traditional role model, the 3PL firm more significantly shares the risk of demand uncertainty with the retailer when offering the trade credit and logistics services together. Thus, the retailer 
benefits from a lower interest rate, the supplier benefits from a larger order quantity, and the 3PL firm benefits from the integration of the financing and its traditional logistics services. This result provides theoretical support to the practice of 3PL firms integrating their logistics services with financial services, such as UPS and others.

Because of the budget constraint, one might expect that neither of our above models can outperform the classic newsvendor model (without budget constraint) in terms of overall supply chain profit. Note that supply chain profit includes the profits of the supplier, retailer, 3PL, and/or the bank and, hence, can be written as follows.

$$
\Pi_{i}^{*}(B)=\mathbb{E}\left\{\min \left[D, Q_{i}^{*}(B)\right]-\left(c_{p}+c_{l}\right) Q_{i}^{*}(B)\right\}
$$

where the subscript $i=t, c l, N$. The following result delivers a somewhat counterintuitive message.

Proposition 4 Compare overall supply chain profits in the traditional role, control role, and classic newsvendor models.

1. The classic newsvendor model outperforms the traditional role model (i.e., $\Pi_{t}^{*}(B) \leq \Pi_{N}^{*}(B)$ ).

2. The control role model outperforms the classic newsvendor model (i.e., $\Pi_{c l}^{*}(B) \geq \Pi_{N}^{*}(B)$ ), as long as $C_{c l}$ is sufficiently low (i.e., $\left.C_{c l} \leq \frac{w-\left(w Q_{c l}^{*}(B)-B\right) h\left(Q_{t}^{*}(B)\right)}{1-H\left[\left(w Q_{c l}^{*}(B)-B\right)\left(1+r_{c l}^{*}(B)\right)\right]}\right)$.

The first statement of Proposition 4 suggests the traditional role model cannot outperform the classic newsvendor in terms of entire supply chain efficiency, which is intuitive because the retailer bears additional financial risk plus the same demand uncertainty as in the classic newsvendor model. As for the control role model, the second statement of Proposition 4 indicates that overall supply chain profit in the control role model outweighs the classic newsvendor model. The rationale behind is that the 3PL firm shares the risk of demand uncertainty with the retailer by lowering the interest rate, such that the retailer orders a larger quantity that consequently yields a higher profit for the entire supply chain. Compared with the traditional role model, the 3PL in the control role model coordinates the supply chain by integrating the financial and logistics services. A lower combined value of product wholesale price and logistics operational cost $\left(C_{c l}\right)$ enables the $3 \mathrm{PL}$ firm to charge a lower interest rate than in the traditional role model. This result conveys the message that an 
integrated service of financing and logistics can coordinate the budget constrained supply chain, and thus is a win-win-win solution to the retailer, the 3PL firm, and the supplier. However, if $C_{c l}$ is too high, the burden of the budget constraint would outpace the benefit of 3PL coordination, such that the classic newsvender model would outperform the control role model in terms of overall supply chain efficiency.

\section{Supplier Credit and Numerical Sensitivity Analysis}

\subsection{Supplier Credit}

In the above discussion, either the bank or the 3PL firm will provide capital to the budgetconstrained retailer, which enables us to focus on the influence of the 3PL firm on the supply chain. In practice, sometimes the supplier will provide trade credit to the budget-constrained retailer; for example, in collaboration with Deutsche Financial Services, Hewlett-Packard (HP) provided trade credit to HP's retailers in Europe in 1998 (Zhou and Groenevelt, 2007). This practice is different from the above control role model because the 3PL firm is not part of the alliance. Although without the monitoring done by the 3PL firm, in a supplier credit model, the retailer has no incentive to conceal the initial budget information because the credit is used to purchase products directly from the supplier. Thus, a supplier credit model can also prevent the asymmetric information problem as observed in the traditional role model.

The supplier's optimal problem under supplier credit is written as follows.

$$
\begin{aligned}
\prod_{s c}^{S}(B)= & \max _{0 \leq r_{s c}(B) \leq \tilde{r}(B)} \mathbb{E}\left\{\min \left[\min \left[D ; Q_{s c}^{*}(B)\right] ;\left(w Q_{s c}^{*}(B)-B\right)\left(1+r_{s c}(B)\right)\right]+B-C_{s c} Q_{s c}^{*}(B)\right\} \\
= & \max _{0 \leq r_{s c}(B) \leq \tilde{r}(B)}\left[\left(w_{p}-c_{p}\right) Q_{s c}^{*}(B)+\left(w Q_{s c}^{*}(B)-B\right)^{+} r_{s c}(B)\right. \\
& \left.+\int_{0}^{\left(w Q_{s c}^{*}(B)-B\right)\left(1+r_{s c}(B)\right)}\left[D-\left(w Q_{s c}^{*}(B)-B\right)\left(1+r_{s c}(B)\right)\right] d F(D)\right] \\
\text { subject to } \quad: \quad & \bar{F}\left(Q_{s c}^{*}(B)\right)=w\left(1+r_{s c}(B)\right) \bar{F}\left[\left(w Q_{s c}^{*}(B)-B\right)\left(1+r_{s c}(B)\right)\right]
\end{aligned}
$$

where $C_{s c}=w_{l}+c_{p}$; the term $\left(w_{p}-c_{p}\right) Q_{s c}^{*}(B)$ represents the wholesale revenue; and the term $\left(w Q_{s c}^{*}(B)-B\right)^{+} r_{s c}(B)+\int_{0}^{\left(w Q_{s c}^{*}(B)-B\right)\left(1+r_{s c}(B)\right)}\left[D-\left(w Q_{s c}^{*}(B)-B\right)\left(1+r_{s c}(B)\right)\right] d F(D)$ denotes the financial benefits. The analysis of the supplier credit model is similar to that of the control role model. Indeed, we can show that, similar to Proposition 3, the supplier credit model dominates 
the traditional role model for both the retailer and the entire supply chain. We now compare the supplier credit model and the 3PL control role model.

Proposition 5 If $w_{l}-c_{l}>w_{p}-c_{p}$, the control role model dominates the supplier credit model for the budget-constrained retailer as well as the entire supply chain; otherwise, the opposite is true.

The term $w_{l}-c_{l}>w_{p}-c_{p}$ means that the 3PL's marginal profit in the control role model is higher than the supplier's marginal profit in the supplier credit model. Proposition 5 suggests that the retailer can benefit from borrowing from a trade credit provider with a higher marginal profit. This result occurs because the higher marginal profit enables the trade credit provider to charge a lower interest rate, which is equivalent to sharing more of the risk of demand uncertainty. Hence, the retailer can order a larger quantity, which leads to higher supply chain efficiency. Thus, if the supplier's marginal profit is lower than the 3PL firm, the retailer will prefer a trade credit from the 3PL firm; or vice versa.

Similar to Proposition 4, we can also show that the supplier credit model can outperform the classic newsvendor model in terms of overall supply chain efficiency. This result occurs because the supplier can significantly coordinate the supply chain by providing trade credit. Thus, in some circumstances, when the benefit of sharing the risk of demand uncertainty overtakes the additional financial risk to the retailer, the retailer orders a larger quantity than the classic newsvendor; thus, overall supply chain profit in the supplier credit model surpasses that of the classic newsvendor model.

\subsection{Numerical Sensitivity Analysis}

We now employ numerical examples to further compare the traditional role, control role, and supplier credit models, and explore the sensitivity of our results to the costs and the retailer's initial budget. In the supply chain configuration, we assume the demand function follows an Exponential distribution with a mean of 1000, which satisfies the characteristics of Assumption A1. Note that our following observation is robust in other distribution functions, such as a uniform distribution, as long as they satisfy Assumption A1. We suppose that $w_{l}=0.3, c_{p}=0.3$, and $c_{l}=0.1 .^{2}$ In the

\footnotetext{
${ }^{2}$ It is worth mentioning that all qualitative results hold with different parameter values. Note that to ensure feasibility we have $w_{p}+w_{l}<1, w_{p} \geq c_{p}$, and $w_{l} \geq c_{l}$.
} 


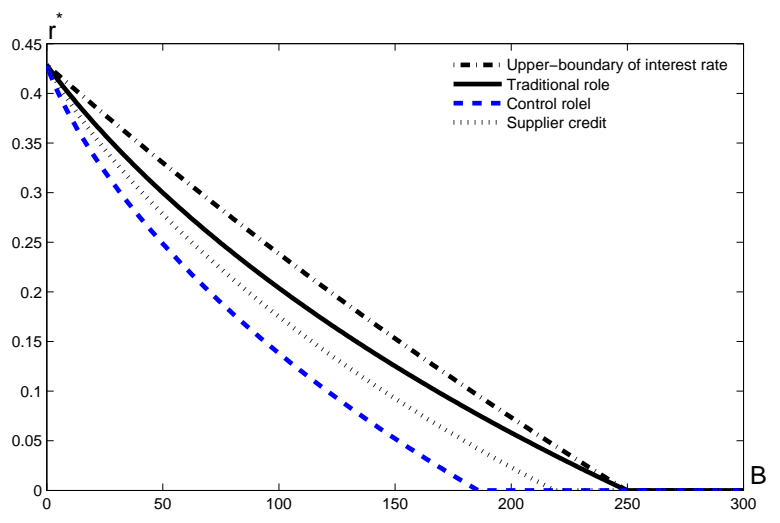

Figure 1: Comparison of $r$ w.r.t. $B$

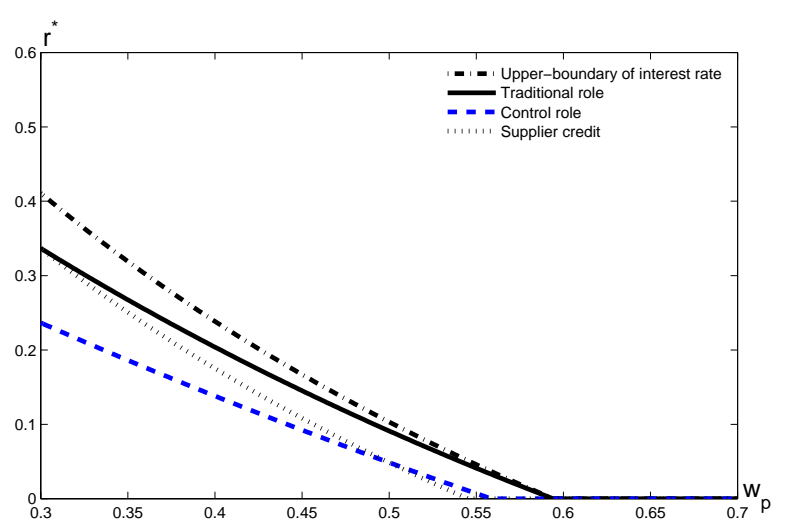

Figure 2: Comparison of $r$ w.r.t. $w_{p}$

sensitivity analysis with respect to (w.r.t.) $B$ where $w_{p}$ is given, we assume $w_{p}=0.4$ (see Figure 1 ); while in the sensitivity analysis w.r.t. $w_{p}$ where $B$ is given, we assume $B=100$ (see Figure 2). We first analyze the sensitivity of the interest rate w.r.t. $B$ and $w_{p}$, as illustrated in Figures 1 and 2 . Figure 1 shows that the optimal interest rate decreases in $B$, which is intuitive, since, from the lender's perspective, the financial risk decreases as the initial budget grows. Moreover, the interest rate is lowest in the 3PL control role model and highest in the traditional role model, which is consistent with the statements in Propositions 3 and 5. In addition, we find that, before any interest rate touches the lower boundary, the interest gaps among different models are increasing as $B$ grows, which suggests that the relative advantage of either the 3PL control role or the supplier credit over the traditional role is more significant when the initial budget is higher.

From the perspective of cost $w_{p}$, Figure 2 demonstrates the control role has the lowest interest rate when $w_{p}<0.5$ (i.e., $w_{p}-c_{p}<w_{l}-c_{l}$ ); when $w_{p}>0.5$, the supplier credit model has the lowest rate; in all situations, the traditional role has the highest interest rate. This observation confirms Proposition 5. Overall, the higher $w_{p}$, the lower the interest rate, which is reasonable because to encourage the retailer to increase the order quantity, the trade credit provider needs to compensate for the retailer's higher wholesale cost. The sensitivity analysis on other parameters $w_{l}, c_{p}$, and $c_{l}$ is similar to that of $w_{p}$, and is thus omitted.

We also examine the sensitivity of supply chain profits in terms of $B$ and $w_{p}$, which is illustrated in Figures 3 and 4. Note that the parameters in Figure 3 are the same as those in Figure 1 and the parameters in Figure 4 are the same as those in Figure 2. Figure 3 demonstrates that the supply 


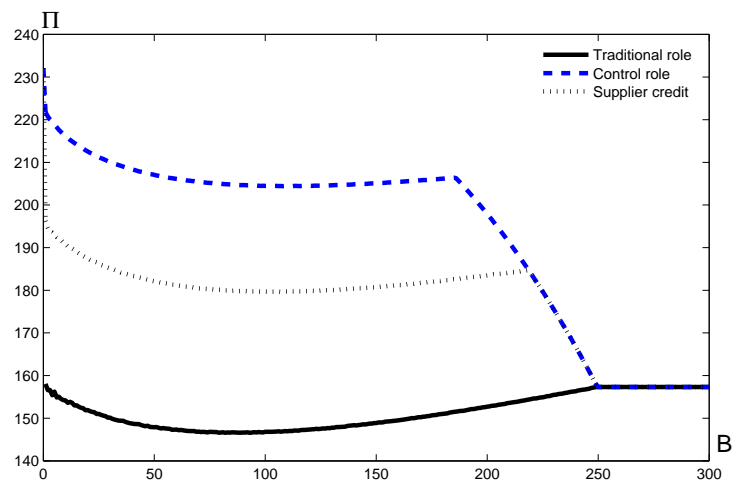

Figure 3: Comparison of $\Pi$ w.r.t. $B$

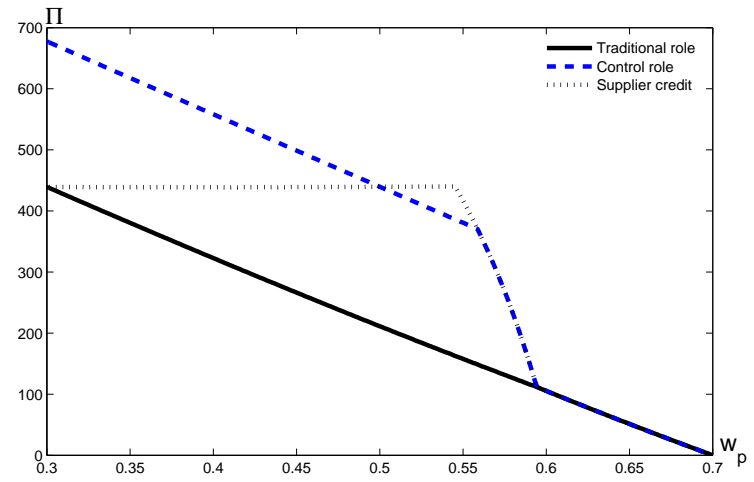

Figure 4: Comparison of $\Pi$ w.r.t. $w_{p}$

chain efficiency is higher in the control role and supplier credit models than in the traditional role, because either the 3PL firm or the supplier shares the risk of demand uncertainty; thus, the retailer orders a higher quantity in both models than in the traditional role model. In this example, the control role model dominates the supplier credit model because the 3PL firm has a higher profit margin. The sequence will be reversed if the supplier credit model has a higher marginal profit. Figure 3 further indicates that overall supply chain profits decrease at first and then increase as $B$ grows before they may decrease again when the interest rates hit the lower boundary. The intuitive explanation is as follows. In the beginning stage with a small budget, the retailer tends to order a higher quantity because the maximal equity to lose is small due to limited liability; however, the retailer's risk increases with a higher budget level and, hence, the order quantity decreases to avoid a potentially huge loss. As $B$ increases, the trade credit provider significantly lowers the interest rate; hence, the tradeoff between loss risk and potential financial benefit leans toward the latter. Thus, the order quantity and overall supply chain profit increase. In this example, $w_{l}+c_{p}$ and $w_{p}+c_{l}$ are lower than $w_{p}+w_{l}$ such that the supply chain profits in the control role and supply credit models decrease again when the interest rates hit the lower boundary. When $B$ is sufficiently high, the retailer does not borrow and the supply chain behaves the same as in the classic newsvendor model. Note that overall supply chain profit in the traditional model role does not surpass that of the classic newsvendor model; however, the control role and supply credit models outperform the classic newsvendor in terms of overall supply chain profit, when $B$ is relatively low or high but still insufficient. These observations are consistent with Proposition 4. 
From another perspective, Figure 4 shows that the wholesale price has a negative synergy on supply chain efficiency in traditional and control roles because the retailer orders less as $w_{p}$ grows. As for the supplier credit model, the change in wholesale price only affects the internal profit distribution between the supplier and the retailer but not the entire supply chain, unless the wholesale price is too high, such that the retailer significantly reduces order quantity. We can also observe that, for the players, the control role model outperforms the supplier credit model when $w_{p}<0.5$ (i.e., $w_{p}-c_{p}<w_{l}-c_{l}$ ); otherwise, the supplier credit model outperforms the others, which again confirms Proposition 5.

It is worth noting that, in real life, both supplier credit and 3PL financing are available and popular among budget-constrained retailers. In terms of 3PL financing, as we previously mentioned, almost all major logistics service providers, such as UPS, Fedex, DHL, Exel, Kuehne and Nagel, Schenker, Panalpina, C.H.Robinson, TNT Logistics, Schneider and NYK Logistics, have provided financial services in addition to their traditional logistics services. As for supplier credit, according to Rajan and Zingales (1995), supplier credit represented $17.8 \%$ of total assets for all American firms, and more than a quarter of total corporate assets in European countries, such as Germany, France, and Italy, in 1991. Our above numerical analysis supports the coexistence of 3PL financing and supplier credit in practice. Nevertheless, as demonstrated previously, the advantage of one financing type over the other depends on whether 3PL firms or suppliers provide a more attractive loan, which hinges on their respective marginal profits, to the budget-constrained retailer.

\section{Conclusion}

This paper investigates the influence of the different roles of a 3PL firm in a supply chain with a budget-constrained retailer. The retailer can borrow capital from a bank or trade credit from a 3PL firm with financial services. We compare the traditional and control roles where the 3PL firm provides only logistics or logistics plus trade credit, respectively. Our analysis indicates the control role model yields higher profits not only for the 3PL firm, but also for the supplier and the retailer. Furthermore, we compare the control role model with the supplier credit model, where the supplier provides trade credit to the retailer. If the 3PL firm's marginal profit in the control role model is higher than that of the supplier in a supplier credit model, the control role model 
outperforms the latter in terms of player's profits; otherwise, the reverse is true. In both the control role and supplier credit models, the budget-constrained retailer could order a larger quantity than that in the classic newsvendor model (without budget constraint); thus, the entire supply chain can perform better in the control role and supplier credit models. The numerical analysis supports the above observations and further indicates that both the control role and supplier credit models can outperform the classic newsvendor model in terms of the entire supply chain profit, especially when the initial budget is low, or high but insufficient.

However, this paper has its limitations. First, similar to the majority of the existing literature, we assume static retail and wholesale prices, which enables us to focus on the efficacy of the 3PL firm in different roles, and further compare them with the supplier credit and classic newsvendor models. When an increasing number of research papers are exploring pricing newsvendors, relaxing the constant retail and wholesale prices is certainly a research priority. Second, although our paper studies both monopolistic and perfect finance markets, the reality of the financial market may be somewhere in between. A trade credit analysis of an oligopolistic finance market would be meaningful and intriguing, although complicated. Third, the risk-neutral assumption has been well taken in the literature and our paper; however, an extension into a risk-averse or risk-seeking model will be expected to give us additional managerial insights. Moreover, in practice, the risk-aversion level could differ between the bank and 3PL firm with financial services. Therefore, comparing models with different risk-averse rates could be another research direction. Last, but not least, extensions to include multiple suppliers, retailers, and 3PL firms are left as an open venue for future research.

\section{Acknowledgements}

The authors are grateful to Editor Peccati and three anonymous referees for their very valuable comments and suggestions. The first author acknowledges support from NSFC (70972046, 70832002), 2010 NCET program, and 2009 Shanghai Pujiang Program. The second author acknowledges support from the National Science Foundation (NSF) through Grant CMMI-0927591. 


\section{References}

Barnett, W. (1997). What's in a name? A brief overview of asset-based lending. Secured lender 53, $80-81$.

Boyabatli, O. and L. B. Toktay (2006). Capacity investment in imperfect capital markets: The interaction of operational and financial decision. Working Paper, TM, INSEAD, Fontainebleau, France.

Burkart, M. and T. Ellingsen (2004). In-kind finance: A theory of trade credit. The American Economic Review 94 (3), 569-590.

Buzacott, J. A. and R. Q. Zhang (2004). Inventory management with asset-based financing. Management Science 50 (9), 1274-1292.

Caldentey, R. and M. B. Haugh (2009). Supply contracts with financial hedging. Operations Research 57(1), 47-65.

Chao, X., J. Chen, and S. Wang (2008). Dynamic inventory management with financial constraints. Naval Research Logistics 55(8), 758-768.

Che, Y. K. and I. Gale (2000). The optimal mechanism for selling to a budget-constrained buyer. Journal of Economic Theory 92, 198-233.

Chen, J. and P. C. Bell (2009). The impact of customer returns on pricing and order decisions. European Journal of Operational Research 195(1), 280-295.

Chung, C.-S., J. Flynn, and J. Zhu (2009). The newsvendor problem with an in-season price adjustment. European Journal of Operational Research 198(1), 148-156.

Dada, M. and Q. Hu (2008). Financing newsvendor inventory. Operations Research Letters 36, $569-573$.

Dammon, R. M. and L. W. Senbet (1988). The effect of taxes and depreciation on corporate investment and financial leverage. Journal of Finance 43, 357-374.

Dotan, A. and S. A. Ravid (1985). On the interaction of real and financial decisions of the firm under uncertainty. Journal of Finance 40, 501-517. 
Gerchak, Y. and Y. Wang (2004). Revenue-sharing vs. wholesale-price contracts in assembly systems with random demand. Production and Operations Management 13(1), 23-33.

Hadley, G. and T. Whitin (1963). Analysis of inventory system. NJ: Prentice-Hill.

Hu, Q. and M. J. Sobel (2005). Capital structure and inventory management. Working paper, Weatherhead School of Management, Case Western Reserve University, USA.

Hu, Q., Y. Wei, and Y. Xia (2010). Revenue management for a supply chain with two streams of customers. European Journal of Operational Research 200(2), 582-598.

Jing, B., X. Chen, and G. Cai (2010). Equilibrium financing in a distribution channel with capital constraint. Working paper, Kansas State University.

Kouvelis, P. and W. Zhao (2008). Financing the newsvendor: Supplier vs. bank, optimal rates, and alterative schemes. Working paper, Olin Business School of Management, Washington University, St. Louis.

Lariviere, M. A. and E. L. Porteus (2001). Selling to the newsvendor: An analysis of price-only contracts. Manufacturing and Service Operations Management 3 (4), 293-305.

Lau, H.-S. and A. H.-L. Lau (1999). Manufacturer's pricing strategy and return policy for a singleperiod commodity. European Journal of Operational Research 116(2), 291-304.

Levaggi, R. (1999). Optimal procurement contracts under a binding budget constraint. Public Choice 101, 23-37.

Lu, M., T. Wu, and H. Yan (2009). Inventory management in decentralized supply chains with logistics service provider. Working paper, The Chinese University of Hongkong.

Mauer, D. and A. J. Triantis (1994). Interactions of corporate financing and investment decisions: A dynamic framework. Journal of Finance 49, 1253-1277.

Mello, A. S. and J. E. Parsons (1992). Measuring the agency cost of debt. Journal of Finance 47, $1887-1904$.

Parlar, M. and Z. K. Weng (2003). Balancing desirable but conflicting objectives in the newsvendor problem. IIE Transactions 35(2), 131-142. 
Rajan, R. and L. Zingales (1995). What do we know about capital structure? Some evidence from international data. The Journal of Finance 53, 80-81.

Thomas, L. (2002). Non-linear pricing with budget constraint. Economic Letters 75, 257-263.

Xu, X. and J. Birge (2008). Operational decisions, capital structure, and managerial compensation: A news vendor perspective. Engineering Economist 53(3), 173 - 96.

Zhou, J. and H. Groenevelt (2007). Impacts of financial collaboration in a three-party supply chain. The Simon School, University of Rochester, Working Paper.

Zhou, Y.-W. and S.-D. Wang (2009). Manufacturer-buyer coordination for newsvendor-typeproducts with two ordering opportunities and partial backorders. European Journal of Operational Research 198(3), 958-974. 